\title{
Bone Alkaline Phosphatase to Total Alkaline Phosphatase Ratio Measurement
}

National Cancer Institute

\section{Source}

National Cancer Institute. Bone Alkaline Phosphatase to Total Alkaline Phosphatase Ratio Measurement. NCI Thesaurus. Code C147294.

The determination of the ratio of bone-specific alkaline phosphatase compared to total alkaline phosphatase present in a sample. The measurement may be expressed as a ratio or percentage. 